\title{
Anesthetic Considerations in Microlaryngoscopy and Direct Laryngoscopy
}

\author{
${ }^{1}$ Anand Nirgude, ${ }^{2}$ Indrani Hemantkumar
}

\begin{abstract}
Patients for microlaryngoscopy (ML Scopy) and direct laryngoscopy (DL Scopy) may present to the anesthesiologist from all ages, including pediatric, adult, and geriatric age groups. Proper preoperative evaluation, adequate intraoperative care, monitoring, and postoperative monitoring will provide successful outcome in these patients. These procedures are daycare procedures. The aim of anesthesiologist while dealing with such patients is maintaining adequate depth of anesthesia, maintaining adequate ventilation to the patients while giving enough time to the surgeon to diagnose and evaluate the definitive cause of airway disease. Anesthesiologists need to share the airway or maintain the ventilation in such a way as to give the surgeon proper and good visualization of the patient's airway. Use of shortacting and potent anesthetic agents will provide adequate intraoperative depth of anesthesia and speed up awakening and hence the postoperative recovery of the patient.
\end{abstract}

Keywords: Anesthesia, Direct laryngoscopy, Microlaryngoscopy.

How to cite this article: Nirgude A, Hemantkumar I. Anesthetic Considerations in Microlaryngoscopy and Direct Laryngoscopy. Int J Otorhinolaryngol Clin 2017;9(1):10-14.

Source of support: Nil

Conflict of interest: None

\section{INTRODUCTION}

Patients for microlaryngoscopy (ML Scopy) and direct laryngoscopy (DL Scopy) may be of all ages, including paediatric, ${ }^{1}$ adult, or geriatric. ${ }^{2}$ They are posted for the procedure for diagnostic or therapeutic purposes. They may present with hoarseness of voice, change of voice, difficulty in breathing, and inspiratory or expiratory stridor. These patients may have associated congenital and acquired conditions other than airway disease, such as smoking-related pulmonary conditions, hypertension, ischemic heart disease, endocrinopathies like diabetes mellitus and thyroid diseases, and cardiac anomalies

\footnotetext{
${ }^{1}$ Assistant Professor, ${ }^{2}$ Professor and Head

${ }^{1}$ Deparment of Anesthesia, Topiwala National Medical College and BYL Nair Hospital, Mumbai, Maharashtra, India

${ }^{2}$ Department of Anesthesia, King Edward Memorial Hospital and Seth Gordhandas Sunderdas Medical College, Mumbai Maharashtra, India

Corresponding Author: Anand Nirgude, Assistant Professor Department of Anesthesia, Topiwala National Medical College and BYL Nair Hospital, Mumbai, Maharashtra, India
}

especially in pediatric age group. The main anesthetic considerations are as follows: ${ }^{3}$

- Adequate preoperative evaluation and optimization

- Maintaining adequate depth of anesthesia intraoperatively to maintain stable hemodynamics in a still patient

- To share the airway in such a way to give good visualization to the surgeon so as to diagnose the pathological conditions

- To give enough time to the surgeon to diagnose and treat the airway diseases

- Protection of lower airway from blood and debris

- Postoperative monitoring and early recovery to fast track the patient.

\section{PREOPERATIVE EVALUATION}

A thorough medical evaluation is necessary for all patients requiring anesthesia. These patients may present with history of hoarseness of voice, voice change (low pitch, coarse fluttering - subglottic/ high pitch, cracking voice, aphonia - glottis), stridor (inspiratory or expiratory). Patients may present with dysphagia. The best breathing position, breathing pattern during sleep give an indication of the severity of the disease. Patients are likely to have cardiovascular (hypertension, ischemic heart disease, coronary artery disease) or respiratory dysfunction (chronic obstructive pulmonary disease). History of previous endoscopic procedures and their outcome is very important. When the lesions occur in or near the airway, there is possibility of life-threatening airway obstruction during the induction of anesthesia. Also, because of manipulation, the airway lesions can cause bleeding or edema, which results in airway occlusion. The difficulties may occur during intubation of trachea. Hence the oropharynx should be evaluated carefully. The range of motion of neck should be examined carefully to assess difficulties with airway management. The radiological investigations and records, such as computed tomography (CT) scan, magnetic resonance imaging (MRI), ${ }^{4,5}$ and X-ray will help to assess the potential difficulties in securing the airway and endotracheal intubation. ${ }^{6}$ Patients may have prolonged endotracheal intubation with previous intensive care unit/neonatal intensive care unit admissions and associated lung pathologies. They should be thoroughly evaluated and optimized 
preoperatively by giving nebulization with $\beta 2$ agonist and adequate hydration.

A discussion with the surgeon is necessary for any potential airway difficulties with anesthesia and to know the plan of surgery.

Prior to anesthesia, the following should be identified.

- Airway assessment: Ease of ventilation, visualization of laryngeal inlet, tracheal intubation

- Direct or indirect laryngoscopy: To assess the severity and size of lesion

- Chest radiography, CT, MRI: For information about the lesions, especially subglottic tracheal lesions that may hamper ventilation.

\section{PREOPERATIVE PREPARATION}

- Cessation of smoking

- Continue bronchodilators

- If with tracheostomy: Steam inhalation, nebulization, and suction

\section{INDICATIONS FOR MICROLARYNGOSCOPY}

- Benign growth nodules, polyps, cysts

- Granulomas

- Vocal cord dysfunction

- Obstructed tumor

- Recurrent respiratory papillomatosis

- Foreign body

\section{PREMEDICATION}

- Sedatives are avoided if any degree of airway obstruction is suspected.

- Anticholinergics are used to decrease secretions and avoid bradycardia.

\section{INTRAOPERATIVE MONITORING}

- Heart rate and rhythm

- Noninvasive blood pressure monitoring

- Pulse oximetry $\left(\mathrm{SpO}_{2}\right)$

- End-tidal carbon dioxide monitoring $\left(\mathrm{ETCO}_{2}\right)$

- Temperature

\section{Additional Monitoring}

- Precordial stethoscope

- Airway pressures

- Invasive monitoring

\section{ANESTHETIC TECHNIQUES FOR MICROLARYNGOSCOPY}

\section{Intubation Techniques}

Advanced airway with ML Scopy endotracheal tube.

\section{Nonintubation techniques}

- Intermittent apnea

- Insufflation technique

- Spontaneous ventilation

- Jet ventilation

\section{INDUCTION OF ANESTHESIA ${ }^{3}$}

Patients who are not at risk of respiratory obstruction can have standard endotracheal following preoxygenation. If obstruction of the airway is anticipated, difficult airway equipments are mandatory. Different size of laryngoscope blades, oral and nasal airway, fibreoptic bronchoscope or video endoscope, rigid bronchoscope, and tracheostomy tray should be available.

Anesthesia is induced with barbiturates like thiopentone sodium $5 \mathrm{mg} / \mathrm{kg}$ iv or Inj. Propofol 2 to $3 \mathrm{mg} / \mathrm{kg}$ and muscle relaxants, such as intravenous (iv) succinylcholine $2 \mathrm{mg} / \mathrm{kg}$. Patient is ventilated with oxygen/ sevoflurane, and endotracheal intubation is performed. Anesthesia is maintained with oxygen, sevoflurane, and intermittent-acting nondepolarizing muscle relaxants like vecuronium bromide.

The surgeon should be present at the time of anesthetic induction. Many times awake intubation of the trachea using topical anesthesia is the technique recommended in these cases. Transtracheal instillation of local anesthetics and superior laryngeal nerve blocks may be useful. In difficult cases fiberoptic laryngoscope should be considered. ${ }^{7}$ Intravenous anesthetics should be used carefully so that adequate and unobstructed respiration is maintained.

Microlaryngeal tube can be used when endotracheal intubation is planned.

\section{MICROLARYNGEAL TUBES OR MALLINCKRODT CRITICAL CARE TUBE}

- Small internal and external diameter

- Can be used orally or nasally.

- 4 to $6 \mathrm{~mm}$ ID, $30 \mathrm{~cm}$ long with standard cuff

- Low-pressure high-volume cuff

- Lies between arytenoid cartilages, leaving at least anterior $2 / 3$ of glottis unobscured

\section{Advantages of Microlaryngeal Tube}

- No special method of introduction - Routine methods suffice

- Protection of lower airway

- Control of ventilation

- Control of airway

- Minimal pollution by volatile agents

- Monitor $\mathrm{ETCO}_{2}$ 


\section{Disadvantages of Microlaryngeal Tube}

- Surgical access and visibility of lesion may be limited

- High inflation pressure may be required through small tube

- Higher resistance, difficulty in suctioning, increased chances of occlusion, and kinking

- Tube-related damage to vocal cords during intubation

- Risk of LASER airway fire

\section{NONINTUBATION TECHNIQUES OF ANESTHESIA IN DIFFICULT MICROLARYNGOSCOPY PROCEDURES ${ }^{8-10}$}

\section{Spontaneous Ventilation}

When there is anticipated difficult intubation and ventilation, spontaneous ventilation technique using inhalational induction with sevoflurane or halothane in oxygen is used. In this technique, laryngoscopy is done and topical local anesthetic is instilled on and above vocal cords and mask ventilation with $100 \%$ oxygen is given. As suitable depth of anesthesia is achieved, rigid laryngoscopy or bronchoscopy is performed. It has its own advantages as there is excellent visualization of the surgical field and ability to evaluate vocal cord function. Also, it is good for otherwise stable patients with compromised airway. Spontaneous ventilation has disadvantages as oxygenation and ventilation is more difficult to assess, surgical field is not still, there is risk of aspiration, and depth of anesthesia is not consistent.

\section{INSUFFLATION TECHNIQUE}

Insufflation technique incorporates the following routes:

- A small catheter in the nasopharynx placed above the laryngeal opening

- A tracheal tube cut short and placed through the nasopharynx emerging just beyond the soft palate

- A nasopharyngeal airway

- Side arm or channel of the laryngoscope

It has some potential disadvantage as there is no control over ventilation. There can be loss of protective airway reflexes and potential for airway soiling. It also causes gastric distention and theatre pollution. It is not suitable for soft floppy lesion.

\section{INTERMITTENT APNEA TECHNIQUE}

Standard anesthesia induction with induction agents as thiopentone sodium 4 to $5 \mathrm{mg} / \mathrm{kg}$ iv and muscle relaxants, such as vecuronium bromide is given and the patient is intubated. Anesthesia is maintained with intermittent nondepolarizing muscle relaxants and inhalational agents like sevoflurane. Patient is handed over to the surgeon after adequate ventilation and surgeon does diagnostic and therapeutic ML Scopy procedure on the patient's airway. Meanwhile, oxygen saturation and other vital parameters are monitored. As the oxygen saturation goes below $97 \%$ the patient is reintubated and ventilated till oxygenation improves. At the end of procedure, patient is reintubated and hyperventilated. Anesthesia is reversed with standard anticholinesterase like neostigmine and anticholinergics like glycopyrrolate.

Intermittent apnea technique has excellent visibility of surgical field and safety in the use of LASER. It has certain disadvantages, such as there is limitation of surgical time, inadequate ventilation, aspiration risk, variable level of anesthesia, ad potential trauma through multiple reintubations.

\section{DIRECT LARYNGOSCOPY ${ }^{11}$}

\section{Definition and Introduction}

It is a procedure i.e., used to obtain a view of the vocal folds and the glottis. Laryngoscopy may be performed to facilitate tracheal intubation during general anesthesia or to secure airway in cardiopulmonary resuscitation or for procedures on the larynx or other parts of the upper tracheobronchial tree.

\section{History}

Alfred Kirstein (1863-1922), Chevalier Jackson (1865-1958), and Gustav Killian (1898-1912) - are all contributors to the introduction of the handheld laryngoscope.

Manuel Garcia (1805-1868) - indirect laryngoscope.

\section{Indications}

Diagnostic indications for laryngoscopy include:

- Stridor, either congenital or acquired

- Subglottic stenosis

- Cysts or masses causing airway obstruction

- Vocal cord palsy

- Foreign bodies Therapeutic indications for laryngoscopy include:

- Subglottic stenosis

- Aspiration/injection of mucous cysts, cystic hygromas

- Papillomas

- Lingual thyroid

- Webs

- Intubation

\section{Instruments/Equipment}

Laryngoscopy can be performed by using rigid or flexible instruments.

- Rigid laryngoscopy: A rigid laryngoscopy may be done by using an indirect or direct method.

- Indirect laryngoscopy: It is performed by using specially designed laryngeal mirrors in combination with a 
headlight. This enables the larynx and the nasopharynx to be visualized. This is frequently used in adults and children. It is often difficult to carry out this procedure. Direct laryngoscopy: ${ }^{11}$ It is performed with handheld curved or straight blade instruments or by using a suspension laryngoscope, which leaves both hands free to manipulate instruments. The curved Macintosh blade and the straight Miller blade laryngoscopes are routinely used.

\section{Equipment for Laryngoscopy ${ }^{12}$}

- Oxygen source and self-inflating ventilation bag (e.g., Ambu bag)

- Face mask

- Oropharyngeal and nasopharyngeal airways

- Tracheal tubes

- Tracheal tube stylet ${ }^{13}$

- Syringe for tracheal tube cuff inflation

- Suction apparatus

- Laryngoscope handle (two)

- Laryngoscope blades: Common blades include the curved (Macintosh) and straight (Miller)

- Stethoscope

\section{Technique}

Sniffing position: ${ }^{14-16}$ The sniffing position is the best starting position for laryngoscopy. In the sniff position, the cervical spine below C5 is relatively straight, there is increasing flexion from $\mathrm{C} 4$ to $\mathrm{C} 2$, and the head is fully extended (occipito-atlantoaxial complex). ${ }^{4,17}$ Neck flexion between $\mathrm{C} 2$ and $\mathrm{C} 4$ is achieved by elevating the head. ${ }^{5,18,19}$

- Flexion at the cervical spine

- Extension at atlanto-occipital joint

- Goal: Alignment of the three axis: Oral axis, pharyngeal axis, and laryngeal axis

\section{Suspension Laryngoscope}

- Frequently carried out by ENT surgeons as this arrangement leaves the surgeon's hands free to use instruments and even to position an operating microscope for precise surgery.

- The surgical procedures that can be done with the suspension laryngoscope include:

- Aspiration/marsupialization of cysts

- Excision of nodules

- Laser vaporization of papilloma

- Injection of bleomycin in cystic hygroma with laryngeal involvement.

\section{Anesthesia Management}

- The requirements of anesthesia for laryngoscopy must be compatible with maximum safety and minimum patient discomfort.
Premedication: With anticholinergics (glycopyrrlate), benzodiazepines, and opioids

Inductionofanesthesia:Thiopentonesodium $(5 \mathrm{mg} / \mathrm{kg}) /$ propofol $(2 \mathrm{mg} / \mathrm{kg})$.

- Only after confirming that the patient can be ventilated by mask (100\% oxygen given for $2-3$ minutes) a longacting muscle relaxant will be administered.

- Four minutes after the injection of NDMR or after the patient is adequately under the inhalational anesthesia, intubation will be attempted by performing direct laryngoscopy.

\section{Laryngoscopy Response}

- Direct laryngoscopy is a noxious stimuli that can provoke adverse responses in the cardiovascular, respiratory, and other physiologic systems.

- The magnitude of the response is greater with increasing force and duration of laryngoscopy.

- Elevation in arterial pressure typically starts within 5 seconds of laryngoscopy, peaks in 1 to 2 minutes, and returns to control levels within 5 minutes. Such hemodynamic changes are undesirable in patients with cardiac disease.

Many techniques have been tried in an effort to attenuate adverse hemodynamic responses to intubation, but none is ideal.

- Prevention by use of an increased depth of anesthesia

- Use of $\mathrm{N}_{2} \mathrm{O}$ with a volatile agent may be beneficial.

- Large doses of narcotics (other than morphine), such as fentanyl $2-3 \mu \mathrm{g} / \mathrm{kg}$, suppress the hemodynamic response but risk prolonged respiratory depression.

- Intubation response suppression using vasodilators, beta blockers/Ca blockers/Xylocard, etc.

- Aerosol or other application of topical anesthetics may be beneficial with a low risk of adverse effects.

- Awake flexible fiberoptic intubation with effective topical anesthesia almost eliminates the hemodynamic response to tracheal intubation.

\section{CONCLUSION}

Different anesthesia techniques have their own advantages and disadvantages. The choice of anesthesia for a given procedure should be decided based on the extent of airway disease in the patient, comorbidities in the patient, and available equipment and resources.

\section{REFERENCES}

1. Mausser G, Friedrich G, Schwarz G. Airway management and anesthesia in neonates, infants and children during endolaryngotracheal surgery. Paediatr Anaesth 2007;17(10): 942-947.

2. McRae K. Anesthesia for airway surgery. Anesthesiol Clin North America 2001 Sep;19(3):497-541, vi. 
3. Brooker CR, Hunsaker DH, Zimmerman AA. A new anesthetic system for microlaryngeal surgery. Otolaryngol Head Neck Surg 1998 Jan;118(1):55-60.

4. Greenland KB, Edwards MJ, Hutton NJ. External auditory meatus-sternal notch relationship in adults in the sniffing position: a magnetic resonance imaging study. $\mathrm{Br} \mathrm{J}$ Anaesth 2010 Feb;104(2):268-269.

5. Hochman II, Zeitels SM, Heaton JT. Analysis of the forces and position required for direct laryngoscopic exposure of the anterior vocal folds. Ann Otol Rhinol Laryngol 1999 Aug;108(8):715-724.

6. Levitan RM. The mystique of direct laryngoscopy. Respir Care 2007 Jan;52(1):21-23.

7. Levitan RM, Heitz JW, Sweeney M, Cooper RM. The complexities of tracheal intubation with direct laryngoscopy and alternative intubation devices. Ann Emerg Med 2011 Mar;57(3):240-247.

8. Barakate M, Maver E, Wotherspoon G, Havas T. Anaesthesia for microlaryngeal and laser laryngeal surgery: impact of subglottic jet ventilation. J Layngol Oto 2010 Jun;124(6):641-645.

9. Aloy A, Schachner M, Cancura W. Tubeless translaryngeal superimposed jet ventilation. Eur Archiv Otorhinolaryngol 1991;248(8):475-478.

10. Orloff LA, Parhizkar N, Ortiz E. The Hunsaker Mon-Jet ventilation tube for microlaryngeal surgery: optimal laryngeal exposure. Ear Nose Throat J 2002 Jun;81(6):390-394.

11. Cozine K, Stone JG, Shulman S, Flaster ER. Ventilatory complications of carbon dioxide laser laryngeal surgery. J Clin Anesth 1991 Jan-Feb;3(1):20-25.
12. Courey MS, Ossoff RH. Laser applications in adult laryngeal surgery. Otolaryngol Clin North Am 1996 Dec;29(6):973-986.

13. Levitan RM, Pisaturo JT, Kinkle WC, Butler K, Everett WW. Stylet bend angles and tracheal tube passage using a straightto-cuff shape. Acad Emerg Med 2006 Dec;13(12):1255-1258.

14. Collins JS, Lemmens HJ, Brodsky JB, Brock-Utne JG, Levitan RM. Laryngoscopy and morbid obesity: a comparison of the "sniff" and "ramped" positions. Obes Surg. 2004 Oct;14(9):1171-1175.

15. El-Orbany M, Woehlck H, Salem MR. Head and neck position for direct laryngoscopy. Anesth Analg 2011 Jul;113(1):103-109.

16. Schmitt HJ, Mang H. Head and neck elevation beyond the sniffing position improves laryngeal view in cases of difficult direct laryngoscopy. J Clin Anesth 2002 Aug;14(5): 335-338.

17. Greenland KB, Edwards MJ, Hutton NJ, Challis VJ, Irwin MG, Sleigh JW. Changes in airway configuration with different head and neck positions using magnetic resonance imaging of normal airways: a new concept with possible clinical applications. Br J Anaesth 2010 Nov;105(5):683-690.

18. Kitamura Y, Isono S, Suzuki N, Sato Y, Nishino T. Dynamic interaction of craniofacial structures during head positioning and direct laryngoscopy in anesthetized patients with and without difficult laryngoscopy. Anesthesiology 2007 Dec;107(6):875-883.

19. Levitan RM, Mechem CC, Ochroch EA, Shofer FS, Hollander JE. Head-elevated laryngoscopy position: improving laryngeal exposure during laryngoscopy by increasing head elevation. Ann Emerg Med 2003 Mar;41(3):322-330. 